\title{
Strategy and business model design in dynamic Telecommunications industries: a study on Italian Mobile Network Operators
}

Antonio Ghezzi; Marcelo Nogueira Cortimiglia; Alejandro Germán Frank

\section{Highlights}

- The framework helps to relate disruptive change factors to business model dimensions

- The framework relates six disruptive change factors to seven business dimensions

- All four Mobile Network Operators that operate in Italy were studied

- Data was collected through face-to-face interviews with top and middle managers

- Results show drivers of disruptive change and their business model implications

\begin{abstract}
The Mobile Telecommunications industry is highly dynamic. Strategic, marketing and technological disruptive changes are the norm in this industry. In such a context, strategy formulation and implementation is a challenge for Mobile Network Operators (MNOs). The aim of this study is to propose an interpretative framework to support MNO's strategic decision-making in a dynamic competitive context characterized by disruptive changes in technology and business dimensions. The proposed framework was applied in an explorative multiple case study conducted on the four MNOs operating in Italy. Data collection involved semi-structured interviews with seven top and middle managers of each company. The application illustrates how the proposed framework allowed the identification of drivers for potentially disruptive change and their implications on Italian MNOs' business models. The research also highlights the main strategic routes that Italian MNOs have at their disposal to face the turbulent competitive times. Although the specific issues reported relate to the Italian context, it can be argued that they are reasonably representative of most Western markets.
\end{abstract}

Keywords: Mobile Telecommunication; Strategic Management; Business model; Dynamic Markets; Disruptive innovation. 


\section{INTRODUCTION}

Given the ubiquity of mobile phones, Mobile Telecommunication is clearly a cornerstone of the Information and Communication Technology (ICT) industry. The relevance of Mobile Telecommunication was initially established during the 1990s, when substantial investments by Mobile Network Operators (MNOs) cemented a vast customer base all over the world. During the following decade and a half, the global Mobile Telecommunication market was characterized by constant growth in terms of users and revenues, most of which associated with voice transmission (Henten et al., 2004).

In recent years, however, this context has changed considerably, with MNOs' focus increasingly shifting towards data transmission and value-added services (Maitland et al., 2002; Peppard and Rylander, 2006; Dunnewijk and Hultèn, 2007; Bouwman et al., 2008). Mobile subscribers growth is stagnating in most countries and, particularly in mature markets such as Western Europe, MNOs face a situation where subscriber saturation and tight cost competition led to voice-related revenues becoming increasingly less profitable (Whitehead et al., 2011; Weber et al., 2011).

Technology innovation is also a constant factor in the Mobile Telecommunication industry (Hamdouch and Samuelides, 2001; Preez and Pistorius, 2003; Fernández and Usero, 2009). On the one hand, the rise of mobile devices tailored to Internet use (i.e., smartphones and tablets) and the diffusion of data-hungry content such as video streaming drive the consumption of data in mobility (Tilson and Lyytinen, 2006; West and Mace, 2010; Whitehead et al., 2011; Reuver et al., 2013). On the other hand, innovation and investments in network infrastructure technology increase the availability of data provision, while lower mobile data tariffs make it more accessible. In this complex competitive environment, elements such as the regulatory backdrop, changing customer needs, and the positioning of competitors and partners alike are some of the additional variables that must be addressed by MNOs when devising their strategies (Preez and Pistorius, 2003; Buellingen and Woerter, 2004; Zhang and Liang, 2011).

Furthermore, MNOs must also contend with a business convergence trend in act in the ICT industry that mirrors the technological convergence of telecommunications, software, Internet and electronic devices (Weber, 2007; Seybold, 2008). This has caused a 
paradigmatic shift in traditional Mobile Telecommunication value networks, as exemplified by the successful foray of Apple in this market and profoundly affects the strategy of all players involved, particularly MNOs (e.g., see Funk, 2009).

It seems clear, then, that the task of setting strategic guidelines in this technology-oriented, multifaceted and turbulent context is particularly daunting. New business models, pricing mechanisms and value network relationships must be designed and implemented in order to cope with the dynamic conditions and continuous technological change (Fernández and Usero, 2009). These efforts require systematic research that considers both the business and technological issues at hand. Thus, important theoretical implications for the Strategic Technology Management discipline can be derived during turbulent times, as demonstrated by classic works such as Henderson and Clark (1990), Anderson and Tushman (1990), Christensen and Rosenbloom (1995) and Pepperd and Rylander (2006).

By studying actions and decisions of firms profoundly affected by contexts of turbulent technologic and market change, insights on strategy-making mechanisms can be formed (Pretorius and Maritz, 2011). In particular, it is possible to study the relationship between the sources of disruptive change and their potential strategic implications by means of the business model dimensions impacted. Thus, the aim of this study is to propose an interpretative framework to support strategic decision making by MNOs in the dynamic Mobile Telecommunication context, characterized by disruptive changes in both technology and business dimensions. The proposed framework helps to relate disruptive change factors to business model dimensions, aiming to develop emergent strategies. This framework was applied in an empirical research conducted at the four MNOs operating in Italy and results allowed to identify drivers of potentially disruptive change and their implications on MNOs' business models.

\section{Theoretical background}

The issue of strategy making in highly dynamic competitive contexts is well established in academic literature. Most of the contributions in this regard can be traced back to the emergent approach to strategy making (Pretorius and Maritz, 2011). Moreover, the impact of 
ICT in business, particularly with the Internet diffusion of the early 90s brought to light a new theme in strategic management that is highly relevant to emergent strategy making: the concept of business model. These topics are briefly addressed next in order to contextualize the empirical research.

\subsection{Emergent strategy making}

Since the early 80s, technology has been incorporated into strategic thinking. This means, basically, to understand how technology relates to the overall business strategy and incorporate this understanding into strategic planning and action.

A first approach to strategy making in technology-oriented industries incorporates a set of theories whose basic assumptions imply that competition is the battle for the most favourable position in a competitive environment, and strategy is how a firm can identify and achieve such position (Porter, 1980). Well known authors that adhere to this line of thought include, for instance, Foster (1985), Shapiro (1989), Hax and Majluf (1991) and Barat (2008). In this so-called "positioning" approach, strategic decisions involve the selection of business areas for a firm to explore and the internal leverage of a firm's resources to position itself in the industry. Thus, to build sustainable competitive advantage, a firm must analyse both endogenous and exogenous factors affecting the industry and its position within it. Technology, according to this approach, is at the same time one of the variables that can be used to implement a firm's strategic choices and a determinant of industry characteristics.

Similar to the positioning approach is the "deliberate" approach to strategy making. Both approaches are highly formalized, making use of established analytical tools and techniques to assess the external environment and devise a rational strategic plan (Mintzberg et al., 1998). Moreover, both the deliberate and positioning approaches assume that the external environment is rather static or, in the best circumstances, changes slowly and at only a few dimensions at the time (Pretorius and Moritz, 2011). This was, in fact, basically true when the theories that underlie this approach were first elaborated. However, in the light of the growing pace of change in technological, economic, social and political scenarios that characterizes the current competitive environment, this appears to be no longer the case. 
Thus, another approach to strategy making became prominent in strategic management literature: the emergent approach, which assumes that strategy making is largely derived from trial-and-error, incremental and mostly bottom-up initiatives (Pretorius and Moritz, 2011). This approach to strategy making assumes not only a highly dynamic environment, but also that changes in this environment are inherently difficult to foresee. Notwithstanding, strategic efforts to induce and, if possible, control change and its effects must be made.

The dichotomy between deliberate/positioning and emergent approaches is analogous to the art versus science interpretations of strategy mentioned by Parnell and Lester (2003), that is, the art perspective assumes that environmental predictability is low while the science perspective assumes that the external environment can be objectively analysed through models and tools. Contrarily to the positioning and deliberate approaches, the emergent approach to strategic technology management considers that a firm's competencies and resources are the main source of competitive advantage, since they change at a much slower pace than technologies or market conditions. This approach builds upon the Resource-Based View theory (Wernerfelt, 1984, Barney, 1986) and has as main exponents authors like Prahalad and Hamel (1990), Teece et al. (1997) and Collis and Montgomery (1995), as well as more recent conceptual deployments such as the Blue Ocean strategy (Kim and Mauborgne, 2004) and Open Innovation (Chesbrough, 2003). In particular, the emergent approach to strategy making considers technology as a variable that induces change either externally, through uncontrolled innovation by competitors or players in other industries, or internally, through planned innovation. This is precisely the case in the Mobile Telecommunication industry, as highlighted by Peppard and Raylander (2006) and Funk (2009).

\subsection{Business Models}

The origins of the business model concept date to the late 1990s, a period of strong technological innovation in the form of the widespread commercial diffusion of the Internet and related ICTs. In fact, de Reuver et al. (2009, p. 2) state that the business model concept "was developed mainly as a response to the need to explicate the value of ICT-driven 
innovations for organizations". Particularly in the context of technology-oriented strategic management, a business model is a "coherent framework that takes technological characteristics and potentials as inputs, and converts them through customers and markets into economic outputs" (Chesbrough and Rosenbloom, 2002, p. 532). More simply, Teece (2010) defines a business model as a conceptual description of how a company creates, distributes and captures value.

The concept of business model has been largely incorporated in strategic management theory (Teece, 2010) as a valuable tool bridging the gap between strategy formulation and implementation in the form of business processes, resources and relationships (Osterwalder, 2004; Shafer et al., 2005). A number of authors have proposed different interpretations on the constituting dynamics of a business model (e.g., Chesbrough and Rosenbloom, 2002; Lumpkin and Dess, 2004; Osterwalder, 2004; Shafer et al., 2005; Ballon, 2007), but most revolve around the following four dimensions: (i) value proposition; (ii) value creation; (iii) value delivery; and (iv) value appropriation.

The value proposition dimension relates to the effective offering in the form of products and/or services that create value for the customer, but also includes target customer selection and segmentation as well as customer acquisition strategies. The value creation dimension reflects the internal organizational characteristics that determine a unique approach to the market and includes the key resources, assets, processes, activities, and competences necessary to create the value proposition. The value delivery dimension refers to how the business is articulated in order to reach its consumers and partners and relates to elements of value network positioning, key partnerships and relationships, delivery and distribution channels, and customer relationship strategies. As it is deeply related to the external value network of actors, the element of value network positioning is of special importance within this dimension. In fact, previous works such as Pepperd and Raylander (2006) and Funk (2009) highlighted the criticality of value network positioning for mobile telecommunication players' business models. Finally, the value appropriation dimension explains how a business captures value and generates profit. It includes the revenue generation and sharing mechanisms among value network partners as well as investment, financing and cost 
structures. The core of a business model is the relationship between the value creation and appropriation dimensions (Amit \& Zott, 2001; Chesbrough, 2007).

Clearly, the concept of business model is closely related to that of emergent strategy making. In a sense, business models can be understood as an abstraction of strategy whose main focus is the internal analysis of the firm focused on value creation, distribution and capture (Casadesus-Masanell and Ricart, 2010). Thus, it can be argued that any single strategy can be achieved through different business model configurations (Seddon et al., 2004). Moreover, each business model is composed by an arrangement of multiple constituting elements, all of which can be varied and experimented with as a response for (or anticipation to) external environment change. Consequently, business models experimentation is a very practical way to implement emergent strategies.

\section{The Framework for Strategy Decision-Making in dynamic contexts}

The proposed framework is based on a comprehensive literature analysis on the topics of strategy making, particularly regarding deliberate and emergent strategy formation mechanisms, and business models. Elaborating on the literature insights it was possible to draw a framework to incorporate disruptive change into strategy making and business model formation in dynamic competitive scenarios - such as Mobile Telecommunication. This framework includes two main elements: (i) a classification schema for disruptive change (Section 3.1); and (ii) guidelines to identify disruptions and incorporate them in the strategy making and, consequently, in business model design (Section 3.2) according to the four business model dimensions mentioned in Section 2.2.

\subsection{Disruptive Change Factors}

The first element of the proposed framework is a classification schema for disruptive change factors that classifies disruptions as environment or enterprise-driven.

Environment-driven changes are exogenous to the company and can be used for both micro and macro-level analysis (i.e., strategy making in a single company or industry analysis). 
Environment-driven changes can be further distinguished as: (i) external innovation; (ii) regulatory change; (iii) customer change; and (iv) competitor strategy change.

In line with Garcia and Calantone (2002), external innovation refers to marketing and/or technological discontinuities at the macro level, that is, on a world, market or industry level. This includes, for instance, the introduction of the App Store distribution model by Apple (a market macro-level discontinuity coupled with a significant technology discontinuity at micro/firm level) or the emergence of tablets and smartphones as main computing platforms (a technology discontinuity at macro level causing significant discontinuity at both marketing and technology micro/firm levels).

Radical regulatory change is almost invariably the result of marketing or technological innovations that require new rules of conduct for companies or individuals operating under the new assumptions. For instance, it was deemed necessary to revamp the regulatory backdrop regarding consumer privacy following the refinement of tools that automatically capture and analyse browsing habits online. There is ample consensus about the telecommunication industry being very tightly regulated all over the world (Bourreau and Dogan, 2001; Grzybowski, 2005). National and transnational authorities regulate universal access provision, competition, minimum investments in infrastructure, spectrum allocation, network sharing, and all forms of consumer protection, including price fixing, privacy protection, mobile advertising and service neutrality.

Changes in customer habits and preferences are also considered exogenous disruptions as only a very limited number of players may be actually capable of generating such large-scale socio-economic phenomena through marketing or technological innovations.

Finally, competitor strategy changes include the relationships between different firms competing in the same industry. A change in the overall strategic focus or in business model dimensions by one player normally affects its competitors, even if the impact is only a change in market share or profit levels. In the mobile telecommunication ecosystem, whose value creation logic is strongly rooted in the value network perspective (Peppard and Rylander, 2006), strategy changes by any player end up impacting not only its competitors, but all other players. 
On the contrary, enterprise-driven changes refer to disruptions to the competitive status quo generated by the firm itself. Therefore, this source of change is only considered for a microlevel analysis (i.e., strategy making in a single company). Basically, enterprise-driven change can be originated from: (i) research \& development (R\&D) efforts; and (ii) emerging resources and competences.

$R \& D$ efforts normally result in innovations that may disrupt the market context at a macro or micro level, from a technological or marketing point of view (Zhang \& Liang, 2012; Garcia $\&$ Calantone, 2002).

Similarly, emerging resources and competences refers to change opportunities arising from a firm's unique processes and intangible resources (Barney, 1986; Prahalad and Hamel, 1990; Teece et al., 1997). While some of these opportunities may be fully developed into marketing or technological innovations, usually these changes will result in improved internal processes, better productivity or increases in intellectual capital that may impact strategic planning and implementation as well as business model deployment.

\subsection{Impact of Disruptive Change Factors}

Disruptive changes are normally associated with changes in business model dimensions and, particularly among these dimensions, the value delivery dimension (Madjdi \& Hüsig, 2011; Zhang \& Liang, 2011). Normally, the direction of this change is from the outside to the inside, that is, a change in market conditions (environment-driven change) impacts (or displays potential to impact) the performance of a business model, as it was designed with different market conditions in mind. However, in a micro-level of analysis, there are cases in which internal factors (enterprise-driven) can be also a source of disruptive changes. So, the proposed framework presented in Figure 1 helps decision-makers and analysts understand how external and internal disruptive change factors (described in Section 3.1) impact each business model dimension (described Section 2.2). A 5-point Likert scale for measuring impact in business model performance is proposed ( $1=$ no impact, $5=$ very high impact $)$. According to this scale, the stronger the impact, the more pressing the need for emergent strategies to deal with that business model mismatch. Such measure should be carried out by 
the decision-makers who could use techniques for qualitative data collection, like focus groups or Delphi, which enables a team discussion for each measure.

Figure 1. Proposed framework to support MNO strategic decision-making in dynamic competitive contexts

As shown in Figure 1, the four business model dimensions (Section 2.2) are disaggregated in elements that are particularly subject to change following disruptions in market conditions (Madjdi and Hüsig, 2011; Zhang and Liang, 2011), that is: (i) Value Proposition: a) target customer segments; b) customer value perception; c) value proposition characteristics; (ii) Value Creation: a) internal value creation resources (e.g., specific processes or organizational structures); (iii) Value Delivery: a) position and role in the value chain;

(iv) Value Appropriation: a) value capture mechanisms (the revenue model); and b) cost structure.

Thus, the main assumption of the proposed framework is that disruptive changes modify the performance of a firm's business model. By analysing the change in the performance of those business model elements - determined by the disruptive change - a "mismatch" would emerge between the current business model and the external or internal environment. The result of this analysis must be fed into strategic planning, thus triggering a strategic replanning process to take into account the disruptive change. In a turbulent competitive context, strategic planning must be continuous and particularly adaptative: the strategic replanning guidelines must then be used as inputs to business model re-design activities. The aim is to prevent the potential mismatch identified and achieve, as soon as possible, the best possible fit between the overall strategy, its implementation in terms of business model, and the characteristics of the competitive environment. Figure 2 presents the working logic of the proposed framework. 


\section{Case analysis: An application of the proposed framework to the Italian MNOs}

In order to illustrate how the proposed interpretative framework can be used to support strategy making and business model design, it was applied to the analysis of the Italian MNOs. Next, the research procedures used for the case study are presented and, after, results are discussed.

\subsection{Research procedures for the case study}

Four explorative multiple case studies were employed as research method for the empirical study (Yin, 1994). The unit of analysis for the case studies was the firm. All four MNOs operating in Italy were studied: Telecom Italia Mobile, Vodafone, Wind, and Tre. The Italian mobile telecommunication market has grown very fast (Mazzoni et al., 2007). Nowadays, this market is highly dynamic and consumer demand has become mature and sophisticated. Considering that the aim of this study was to understand this market at a macro-level (i.e., industry analysis), only environment-driven changes were considered. As pointed out in Section 3.2, enterprise-driven changes are focused at the micro-level of each single company and, therefore, were not analyzed.

Data collection was conducted through seven face-to-face semi-structured interviews with top managers actively involved in formulating their company's strategy and responsible for the following organizational units at each company: Operations (Value-Added Services), Operations (Broadband Content), Market Innovation \& Research, Planning \& Control (Technology \& Operations), Operations (Mobile Broadband), New Project Development, and Technology Strategy. The average duration of each interview was one hour and all interviews were recorded. Secondary sources such as internal company documents, news published in specialized publications, reports and white papers were also used.

Data analysis for the four case studies was conducted in parallel, with combined cross-case analysis of case study write-ups. Data analysis procedures included coding analysis of the interview transcripts and secondary data (Auerbach \& Silverstein, 2003; Ritchie \& Lewis, 2003). The empirical study took place between October 2011 and January 2012. 


\subsection{Disruptive Change Factors}

The first element of the proposed framework is the identification of disruptive change affecting the industry. In the case of Italian MNOs, interviewees pointed out as the main specific change factors (i) the relatively recent increase in mobile data traffic coupled with (ii) the constant decrease in revenues from voice traffic. Data traffic increase has been explained by interviewees as a direct result of a number sub-factors, such as the diffusion of value-added services by over-the-top operators, the growing popularity of bandwidth consuming services such as video streaming and peer-to-peer, the emergence of more accessible data traffic plans, the popularity of social networking services (some of which include rich-media applications such as photo and video sharing), the diffusion of easy-touse Internet-capable smartphones and decisive marketing efforts by Italian MNOs to prompt the use of value-added services.

It is opportune to note that interviewees see the increase in data traffic not only as a driver of business, but also as a technological threat. This is so because mobile bandwidth is a scarce resource that, according to some forecasts, can be saturated in the near future if the pattern of traffic growth intensifies. In fact, already in 2007 it has been pointed out that spectrum management policies can strongly impact MNOs' 4G network business models (Bohlin, 2007).

On the other hand, Italian MNOs seem to relate the decrease in voice-related revenues to the following sub-factors: market saturation (which leads to extreme cost competition in order to shift market shares), emergence of voice-over-IP (VoIP) services (Shin, 2012), and diffusion of social networking services. The latter two factors are seen by interviewees as substitute products that circumvent the traditional MNO value appropriation mechanism: the mobile phone bill.

Figure 3 shows how the external specific change factors identified for the Italian MNOs (columns) are related to the classification schema for disruptive change factors proposed in Section 3.1 (rows). As shown in this figure, interviewers related the specific factors to more than one single sub-category of disruptive change.

Figure 3. Classification Schema for Environment-driven Disruptive Change Factors applied to Italian MNOs 


\subsection{Impact of Disruptive Change Factors}

Beyond identifying factors of disruptive change in act in the Italian Mobile Telecommunication market from the MNOs' point of view, the research attempted to understand their impact in the operationalization of MNOs' strategies, i.e., their business models. Figure 4 summarizes the findings, showing only the specific factors previously mentioned in the columns of Figure 3.

Figure 4 - Impact of disruptive change factors in Italian MNOs' business models

As Figure 4 shows, the most significant impact of the main change factors (increase in data traffic and decrease in voice revenues) lies in the value proposition dimension. For instance, the combined effect of increased smartphone and value-added services diffusion with more accessible data traffic plans tend to change end consumers' perceived needs and, consequently, the value these customers expect from a MNO - shifting from a provider of telephone (voice) services to a provider of data connections. This has strong implications for quality of service, as data provision in mobility to an ever growing number of different computational devices is a much more complex issue than providing point-to-point connection for voice communication.

Moreover, the change factors deeply impacted MNO's value network positioning, thus impacting on the value delivery dimension of MNOs' business models. This is particularly true in the case of the Mobile Value Added Services \& Internet market, and is evident through a number of elements highlighted by interviewees during the empirical research.

The first value network-related impact mentioned is the arrival of new players. In the studied market, this means Web-originated companies expanding their value proposition to the Mobile delivery channel, as well as a large number of emergent independent or semiindependent application developers and mobile middleware technology providers. Specific strategic relationships with each type of new player have to be formulated and implemented 
by Italian MNOs, with evident impact in coordination resources. Conversely, a higher level of strategic complexity is observed in these relationships, with the introduction of coopetition dynamics with device manufacturers and web companies, open innovation agreements and partial role overlapping in some cases (for instance, between device manufacturers and MNOs for direct customer ownership or billing).

Impacts in the value appropriation dimension seem to be related to the need of both creating new revenue mechanisms and revamping cost structures to handle market pressure for more accessible data plans and decreasing voice-related revenues. Although experiments with unlimited data plans were made in the past, these are now almost universally absent from MNOs' offerings. MNOs' business models' value appropriation mechanisms can benefit from the exclusive payment channel they possess, the phone billing. Moreover, it seems that the consolidation of VoIP and other Web-based communication services in mobility is not directly reducing revenues derived from text messages, but further pressing the cost structure for data provision.

Finally, it seems that change factors do not strongly impact the value creation dimension, as most organizational capabilities remain unaffected. A single exception would be marketingrelated capabilities that have to cope with increased rivalry for decreasing voice-related revenues. Some technical capabilities such as infrastructure management necessary to handle increased data traffic from smartphones and other mobile computing devices, however, are mildly impacted.

\subsection{Potential Strategic Directions for Italian MNOs}

The empirical research also generated an understanding of the potential strategic directions MNOs are evaluating, given the change factors identified and the potential impacts assessed. A first set of strategic actions are aimed at solving the issue of bandwidth scarcity. These include revamping the value appropriation dimension of MNOs' business models in order to align revenue mechanisms with cost structures necessary to expand network infrastructure. This may be deployed through the limitation of flat data traffic plans by a network cap or contract diversification according to user choices such as peer-to-peer usage, quality of service desired/required based on usage profile, and time of day connections are established. 
Conversely, MNOs can also try to explore additional frequencies made available through the digital dividend, that is, the switch-off between analogic and digital transmissions taking place in most Western countries.

A second potential strategic solution to the bandwidth scarcity issue lies in increased investments in network infrastructure, with consequent expansion of capacity. There are also alternatives of flexible spectrum coordination such as dynamic spectrum allocation and spectrum pooling. In this context, Ballon and Delare (2009) discuss the use of a coordinating agent to allow a free market approach where MNOs and other players involved directly control spectrum allocation. However, such an approach would require a thoroughly revision in MNOs business models and may not be fully feasible from a practical point of view.

The research also highlighted a set of strategic actions aimed at the issue of decreasing voice-related revenues. The first option is revamping the value appropriation dimension of MNOs' business models. This can be achieved, for instance, by contract differentiation (with or without VoIP access, for instance) or price reduction actions in order to improve market share (a strategy successfully employed by Mobile Virtual Network Operators all over Europe) (Fernández and Usero, 2009).

If these strategic actions are not enough to minimize losses or create enough profits for future growth, MNOs have also at their disposal the possibility of exploring the disruptive changes at hand through specific strategic investments in innovative marketing opportunities. However, the need for the adequate fit between these innovative marketing opportunities and firms' competencies and distinctive value creation assets has to be highlighted. For instance, Telecom Italia Mobile has decided to invest in areas such as Mobile Payment, eBooks, OTT TV, target advertising, Cloud Computing, and Application Stores. In this case, the MNO was forced to face the disruption caused by Apple's marketing and technological innovations, which have changed the distribution paradigm for mobile digital content from Mobile Portals to Application Stores. The research suggests that MNOs willing to develop their own Application Stores must be able to guarantee a number of critical success factors dictated by the market. These include a large user base that can be easily reached (which has to be effectively communicated to potential application 
developers), and a sustainable business model for third party developers coupled with a proven technical infrastructure for application development (which also needs to be effectively distributed to application developers).

\subsection{Future Strategic Scenarios for Italian MNOs}

Finally, the research provided a summary of Italian MNOs' future strategic positioning scenarios. In short, Italian MNOs must choose their own role in the Mobile Internet convergence scenario. Three potential future scenarios were evidenced through the empirical research.

If Italian MNOs wish to maintain a focal role in the future Mobile Internet value network, current strategy makers understand that they must manage three areas contemporaneously: (i) customer relationship (i.e., the value delivery business model dimension), where they can build sustainable competitive advantage through economies of scope; (ii) content commercialization and innovation, focusing in innovative services and diminishing the timeto-market of new content and services; and (iii) infrastructure management, focusing in network access services and mediation capability, where their competitive differential also lies in economies of scale. In other words, Italian MNOs that wish to retain their focal role must manage and control the value network through the lens of the "Smart Pipe" analogy, i.e., exploring the opportunities brought by the network functionalities and managing the quality of service as source of competitive advantage. An example of business model implementation of the Smart Pipe concept was provided by one of the interviewees: by managing data traffic functionalities, it is possible to create "preferred routes" for companies willing to pay for superior network connection speed to costumers accessing their sites or applications. A second potential business model that illustrates the Smart Pipe vision relies on the use of core network functionalities by third parties in B2B arrangements. Functionalities that can be explored in these business models include location-based services or the potential to bill the user through the MNO's Sim card, bypassing the need for credit cards. The MNO, thus, would "rent" its technological assets and capabilities to third parties able and willing to develop and manage a profitable business model around them. Normally, 
value appropriation in these cases can take the form of revenue sharing mechanisms, but other options are also available.

Another strategic option suggested in this research for MNOs in the near future goes beyond the role of Smart Pipe. Depending on the technological and marketing evolution of the competitive environment, MNOs should play the role of "Value Network Orchestrators", which is highlighted by Weber et al. (2011) as a type of competition that lacks in European operators, if compared with US or Japan. According to evidence brought to light during the empirical research, this option implies in two main strategic courses of action for Italian MNOs. The first one requires that MNOs be able to achieve a state of equilibrium in their relationships with other large players in the value network, such as device manufacturers and web companies. The other course of action is to pursue the development of open technological platforms compatible with as many different devices as possible. Evidently, there is a delicate trade-off in the actual strategic actions to be taken, as pursuing open platforms may be contrary to the interests of device manufacturers. The specific actions necessary to achieve a role of "Value Network Orchestrator" depend, evidently, on the future developments in the Mobile Internet convergence scenario, but all Italian MNOs are aware of this option.

Finally, a third analogy for the future strategic role of MNOs was suggested by the interviewees. That is the role of "Innovation Coordinator" within the value network. This requires the MNOs to relinquish operational activities related to content creation and development of new products and services to specialized, dedicated third parties. Thus, MNOs become coordinators of the development ecosystem and, if the transition is managed correctly, they will be able to keep a central role in the value network without the high costs related to development of innovative products. This is a similar role that is currently played by Apple in the closed ecosystem it created for its devices. The Innovation Coordination is aligned with Zhang and Liang's (2011) findings for Chinese MNOs. To these authors, MNOs should play a central role in the ecosystem by managing the entire value chain and setting up proper value-sharing mechanisms with their partners. 
Obviously, these three scenarios are not mutually exclusive. Instead, they are complementary - each MNO will certainly look for a role adequate to its strategic characteristics, competences, assets and capabilities.

\section{CONCLUSIONS}

This study presented an interpretative framework to support strategic decision-making in highly turbulent competitive scenarios. This is precisely the case of the Mobile Telecommunication industry in recent years, as the technological convergence between Internet and Mobile has brought to light a number of business consequences. By studying the strategic decision-making process of top and middle managers of firms operating at the core of the affected industry, it was possible to understand how strategy makers identify the drivers of potentially disruptive change and, more importantly, how they perceive the impact of change factors in their business models.

Moreover, the research highlighted the main strategic routes MNOs have at their disposal to face the turbulent competitive times ahead. These include specific strategic actions to cope with the issues of mobile bandwidth scarcity and decreasing voice-related revenues. A summary of MNOs future strategic positioning options is also provided.

Given the exploratory nature of the research reported, its findings from provide a contribution which refers to both the theoretical and the practical domains.

With reference to theory, the study represents an industry-specific contribution to the understanding of strategy making and business model design in dynamic contexts. More specifically, the study suggests that external or internal disruptive change affects a firm's strategy down at the level of business model elements. Thus, the business model may serve as a tool to: i) spot discontinuities; and ii) trigger a re-planning process aimed at generating a strategy that is consistent with the emerging environment. By suggesting a "meta-role" for the business model as a link between strategic planning and change, the study positions itself in the broader debate concerning the role of business model design within the strategy decision-making process: hence, the framework supports the operationalization of the analysis of the strategy-discontinuity relationship, and may be valuable for both researchers and practitioners in the field of Strategic Management. 
Indeed, beyond such implications for theory, the study's main contribution is managerial, and lies in the detailed analysis of the Mobile Telecommunication market in a context of technology and business convergence. The richness of data available made it possible to draw a clear picture of the challenges and opportunities MNOs face. Moreover, the framework supports the managers in their activities of planning and forecasting when confronted with disruptive external and internal changes. Although the specific issues were analysed in the Italian context, it can be argued that they are reasonably representative of most Western markets and, thus, results and insights can be somewhat generalizable: this argument stems from the recognition that the environment-driven disruptive change factors have a global - rather than local - reach and magnitude, being experienced by most of the mature Western Mobile markets such as the UK, France and Germany; and the enterprisedriven factors related to $R \& D$ investments and the rise of innovative resources and competencies characterize other Western MNOs as well. Evidently, explanatory and descriptive future research on different international markets is necessary in order to expand and validate the findings reported, so as to allowing a comparison of results while overcoming the additional limitations deriving from potential observer bias in the activities of case data gathering and analysis.

\section{REFERENCES}

Anderson, P. \& Tushman, M.L. (1990). Technological discontinuities and dominant designs: a cyclical model of technological change. Administrative Science Quarterly, 35(4):604-633.

Auerbach, C.F. \& Silverstein, L.B. (2003). Qualitative Data - An Introduction to Coding and Analysis, New York University Press.

Ballon, P. (2007). Business modelling revisited: the configuration of control and value. Info, 9(5): 619.

Ballon, P. \& Delaere, S. (2009). Flexible spectrum and future business models for the mobile industry. Telematics and Informatics, 26(3):249-258.

Barat, S. (2008). A new model for competitive warfare and sustained advantage. Strategic Change, 17:269-280.

Barney, J. (1986). Strategic factor markets: expectations, luck, and business strategy. Management Science, 32(10):1231-1241. 
Bohlin, E. (2007). Business models and financial impacts of future mobile broadband networks. Telematics and Informatics, 24(3):217-237.

Bouwman, H., Carlsson, C., Walden, P. \& Molina-Castillo, F. (2008). Trends in mobile services in Finland 2004-2006: from ringtones to mobile internet. Info, 10(2): 75-93.

Buellingen, F. \& Woerter, M. (2004). Development perspectives, firm strategies and applications in mobile commerce. Journal of Business Research, 57(12):1402-1408.

Bourreau, M. \& Dogan, P. (2001). Regulation and innovation in the telecommunications industry. Telecommunications Policy, 25(3):167-184.

Casadesus-Masanell, R. \& Ricart, J.E. (2010). From strategy to business models and onto tactics. Long Range Planning, 43(2-3):195-215.

Chesbrough, H. (2003). Open Innovation - The New Imperative for Creating and Profiting from Technology, Harvard Business School Press.

Chesbrough, H. \& Rosenbloom, R.S. (2002). The role of the business model in capturing value from innovation: evidence from Xerox Corporation's technology spin-off companies. Industrial and Corporate Change, 22 (3):529-555.

Collis, D.J. \& Montgomery, C.A. (1995). Competing on Resources: Strategy in the 1990s, Harvard Business Review, 73:118-128.

Dunnewijk, T. \& Hultèn, S. (2007). A brief history of mobile communication in Europe, Telematics and Informatics, 24(3):164-179.

Fernández, Z. \& Usero, B. (2009). Competitive behavior in the European mobile telecommunications industry: Pioneers vs. followers. Telecommunications Policy, 33(7):339-347.

Foster, R.N. (1985). Timing technological transitions, Technology in Society, 7:127-141.

Funk, J.L., 2009. The emerging value network in the mobile phone industry: The case of Japan and its implications for the rest of the world. Telecommunications Policy, 33(1-2):4-18.

Garcia, R., Calantone, R., 2002. A critical look at technological innovation typology and innovativeness terminology: a literature review, The Journal of Product Innovation Management, 19:110-132.

Grzybowski, L. (2005). Regulation of mobile telephony across the European Union: An empirical analysis. Journal of Regulatory Economics, 28(1):47-67.

Hamdouch, A. \& Samuelides, E. (2001). Innovation's dynamics in mobile phone services in France. European Journal of Innovation Management, 4(3):153-162.

Hax, A.C. \& Majluf, N.S. (1991). The Strategic Concept and Process: A Pragmatic Approach, Prentice Hall.

Henderson, R.M. \& Clark, K.B. (1990). Architectural innovation: the reconfiguration of existing product technologies and the failure of established firms, Administrative Science Quarterly, 35(1):930 .

Henten, A., Olesen, H., Saugstrup, D. \& Tan, S.-E. (2004). Mobile communications: Europe, Japan and South Korea in a comparative perspective. Info, 6(3):197-207.

Kim, W. C. \& Mauborgne, R. (2007). Blue Ocean Strategy: How to Create Uncontested Market Space and Make the Competition Irrelevant, Harvard Business School. 
Lumpkin, G.T. \& Dess, G.G. (2004). E-Business Strategies and Internet Business Models: How the Internet Adds Value. Organizational Dynamics, 33(2):161-173.

Madjdi, F. \& Hüsig, S. (2011). The response strategies of incumbent mobile network operators on the disruptive potential of public W-LAN in Germany. Telecommunications Policy, 35(6):555-567.

Maitland, C.F., Bauer, J.M. \& Westerveld, R. (2002). The European market for mobile data: evolving value chains and industry structures. Telecommunications Policy, 26(9-10):485-504.

Mintzberg, H., Ahlstraand, B. \& Lampel, J. (1998). Strategy safari: a guided tour through the wilds of strategic management. New York: Free Press.

Osterwalder, A. (2004). The Business Model Ontology: A Proposition in a Design Science Approach. Doctoral Thesis on Management Informatics, Lausanne: Ecole des Hautes Etudes Commerciales, Universite de Lausanne.

Parnell, J.A. \& Lester, D.L. (2003). Towards a philosophy of strategy: reassessing five critical dilemmas in strategy formulation and change. Strategic Change, 12(6):291-303.

Peppard, J. \& Rylander, A. (2006). From Value Chain to Value Network: an Insight for Mobile Operators. European Management Journal, 24(2-3):128-141.

Porter, M.E. (1980). Competitive Strategy, New York: Free Press.

Prahalad, C.K. \& Hamel, G. (1990). The Core Competency of the Corporation. Harvard Business Review, 68(3):79-91.

Preez, G.T. du, Pistorius, C.W.I. (2003). Analyzing technological threats and opportunities in wireless data services. Technological Forecasting and Social Change, 70(1):1-20.

Pretorius, M. \& Maritz, R. (2011). Strategy making: the approach matters. Journal of Business Strategy, 32(4):25-31.

Reuver, M. de, Bouwman, H. \& MacInnes, I. (2009). Business model dynamics: a case survey. Journal of Theoretical and Applied Electronic Commerce Research, 4(1):1-11.

Reuver, M. de, Ongena, G. \& Bouwman, H. (2013). Should mobile Internet be an extension of the fixed web? Fixed-mobile reinforcement as mediator between context of use and future use. Telematics and Informatics, 30(2):111-120.

Ritchie, J. \& Lewis, J. (2003). Qualitative Research Practice - A Guide for Social Sciences Students and Researchers, SAGE Publications.

Seddon, P.B., Lewis, G., Freeman, P. \& Shanks, G. (2004). Business models and their relationship to strategy. In: Currie, W. (ed.). Value creation from e-business models. Burlington: ButterworthHeinemann.

Seybold, A.M. (2008). The convergence of wireless, mobility, and the Internet and its relevance to enterprises. Information Knowledge Systems Management, 7(1-2):11-23.

Shafer, S.M., Smith, H.J., Linder, J.C. (2005). The power of business models, Business Horizons, 48(3):199-207.

Shapiro, C. (1989). The theory of business strategy, Rand Journal of Economics, 20:125-137.

Shin, D.-H. (2012). What makes consumers use VoIP over mobile phones? Free riding or consumerization of new service. Telecommunications Policy, 36(4):311-323. 
Teece, D.J., Pisano, G., Shuen, A. (1997). Dynamic capabilities and strategic management, Strategic Management Journal, 18(7):509-533.

Teece, D.J. (2010). Business models, business strategy and innovation. Long Range Planning, 43:172-194.

Tilson, D., Lyytinen, K. (2006). The 3G transition: Changes in the US wireless industry. Telecommunications Policy, 30(10-11):569-586.

Weber, A. (2007). The convergence of mobile data phones, consumer electronics, and wallets: Lessons from Japan, Telematics and Informatics, 24(3):180-191.

Weber, A., Haas, M. \& Scuka, D. (2011). Mobile service innovation: A European failure. Telecommunications Policy, 35(5):469-480.

Wernerfelt, B. (1984). A resource-based view of the firm. Strategic Management Journal, 5(2):170 180.

West, J., Mace, M. (2010). Browsing as the killer app: Explaining the rapid success of Apple's iPhone. Telecommunications Policy, 34(5-6):270-286.

Whitehead, M., Phillips, T., Page, M. \& Molina, M. (2011). European Mobile Industry Observatory 2011. GSM Association Report, November 2011. Available at < http://www.gsma.com/publicpolicy/wp-content/uploads/2012/04/emofullwebfinal.pdf>.

Zhang, J., Liang, X.-J. (2011). Business ecosystem strategies of mobile network operators in the 3G era: The case of China Mobile. Telecommunications Policy, 35, 156-171.

Yin, R.K. (1994). Case Study Research: Design and Methods, Sage Publications. 2nd edition. 


\begin{tabular}{|c|c|c|c|c|c|c|c|c|c|}
\hline & & & & & & & & & \\
\hline & & & & Cha & gges in bu & iness mod & el dimensi & & \\
\hline & & & & ue Proposit & & $\begin{array}{c}\text { Value } \\
\text { Creation }\end{array}$ & $\begin{array}{c}\text { Value } \\
\text { Delivery }\end{array}$ & $\begin{array}{r}\text { Val } \\
\text { Approp }\end{array}$ & $\begin{array}{l}\text { ue } \\
\text { riation }\end{array}$ \\
\hline $\begin{array}{l}\text { Disruptive } \\
\text { Change } \\
\text { Categories }\end{array}$ & Disruptive Change Factors & $\begin{array}{l}\text { Specific } \\
\text { Elements }\end{array}$ & $\begin{array}{l}\text { Target } \\
\text { Customer }\end{array}$ & $\begin{array}{l}\text { Customer } \\
\text { value } \\
\text { perception }\end{array}$ & $\begin{array}{l}\text { Value } \\
\text { propor- } \\
\text { sition } \\
\text { charact. }\end{array}$ & $\begin{array}{c}\text { Internal } \\
\text { value } \\
\text { creation } \\
\text { resources } \\
\end{array}$ & $\begin{array}{c}\text { Value } \\
\text { Network } \\
\text { Positio- } \\
\text { ning } \\
\end{array}$ & $\begin{array}{l}\text { Value } \\
\text { capture } \\
\text { mecha- } \\
\text { nisms } \\
\end{array}$ & $\begin{array}{c}\text { Cost } \\
\text { structure } \\
\end{array}$ \\
\hline & External innovation & & & & & & & & \\
\hline Environment- & Regulatory change & & & & & & & & \\
\hline driven & Customer change & & & & & & & & \\
\hline & Competitor strategy change & & & Factors & IIIPact & & & & \\
\hline Enterprise- & R\&D Efforts & & & & & & & & \\
\hline driven & Emerging resources and competences & & & & & & & & \\
\hline
\end{tabular}

Figure 1. Proposed framework to support MNO strategic decision-making in dynamic competitive contexts

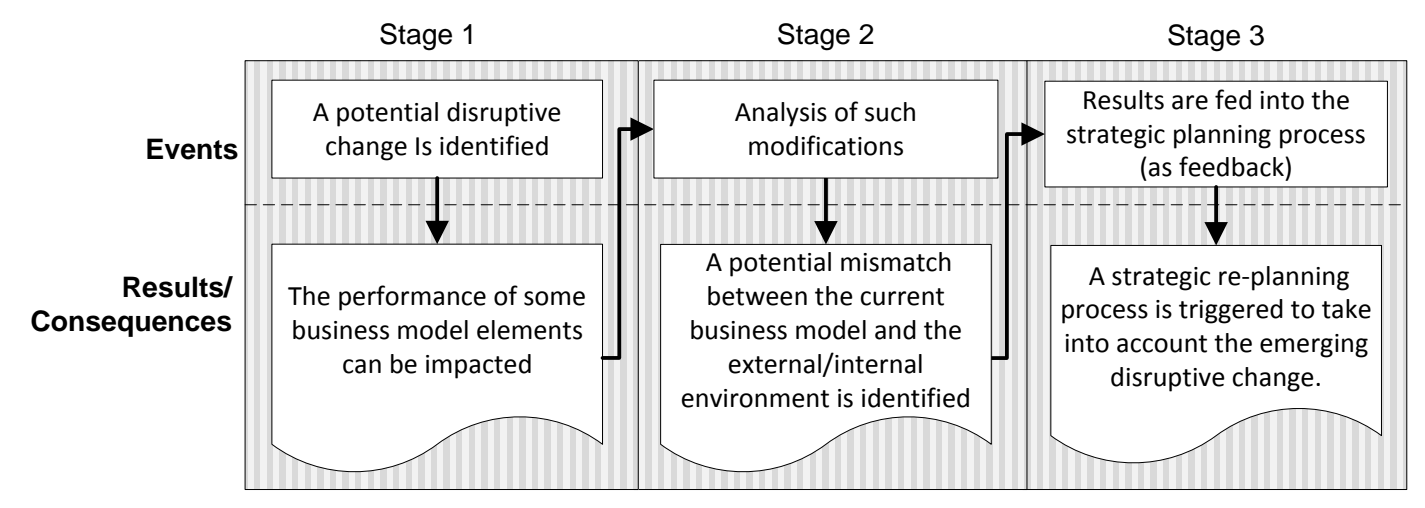

Figure 2. Working logic of the proposed framework 


\begin{tabular}{|c|c|c|c|c|c|c|c|c|c|c|}
\hline \multirow{2}{*}{\multicolumn{2}{|c|}{ Disruptive Change Factors }} & \multicolumn{9}{|c|}{ Specific factors associated with disruptive change } \\
\hline & & \multicolumn{4}{|c|}{ Increase in data traffic } & \multirow{2}{*}{\multicolumn{2}{|c|}{$\begin{array}{l}\text { Smart- Marketing } \\
\text { phones efforts }\end{array}$}} & \multicolumn{3}{|c|}{ Decrease in voice revenues } \\
\hline Categories & Sub-Categories & $\begin{array}{l}\text { Diffusion } \\
\text { of VAS } \\
\text { (OTT) }\end{array}$ & $\begin{array}{l}\text { Bandwith } \\
\text { consuming } \\
\text { services }\end{array}$ & $\begin{array}{c}\text { Acessible } \\
\text { data traffic } \\
\text { plans }\end{array}$ & $\begin{array}{c}\text { Social } \\
\text { networking } \\
\text { services }\end{array}$ & & & $\begin{array}{l}\text { Market } \\
\text { saturation }\end{array}$ & $\begin{array}{l}\text { Emergence } \\
\text { of Voip }\end{array}$ & $\begin{array}{c}\text { Social } \\
\text { networking } \\
\text { services }\end{array}$ \\
\hline \multirow{4}{*}{$\begin{array}{l}\text { Environment } \\
\text {-driven }\end{array}$} & External innovation & $x$ & $x$ & & $x$ & $x$ & & & $x$ & $x$ \\
\hline & Regulatory change & & & $\mathrm{x}$ & & & & & & \\
\hline & Customer change & & $x$ & $x$ & $x$ & $x$ & & & & \\
\hline & Competitor strategy & $x$ & & $x$ & & & $x$ & $\mathrm{x}$ & & \\
\hline \multirow{2}{*}{\begin{tabular}{|l} 
Enterprise \\
-driven
\end{tabular}} & R\&D efforts & & & & & & el analys & & & \\
\hline & $\begin{array}{l}\text { Emerging resources } \\
\text { and competences }\end{array}$ & \multicolumn{9}{|c|}{ Not considered for macro-ien } \\
\hline
\end{tabular}

Figure 3. Classification Schema for Environment-driven Disruptive Change Factors applied to Italian MNOs

\begin{tabular}{|c|c|c|c|c|c|c|c|c|c|}
\hline \multirow{3}{*}{$\begin{array}{l}\text { Deruptive } \\
\text { Change } \\
\text { Categaries }\end{array}$} & \multirow{3}{*}{\multicolumn{2}{|c|}{ Detruptive Change Factors }} & \multicolumn{7}{|c|}{ Changes in Husiness Model Dimensions } \\
\hline & & & \multicolumn{3}{|c|}{ Vilue Propasition } & \multirow{2}{*}{ 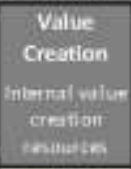 } & \multirow{2}{*}{ 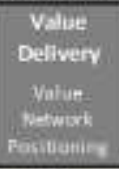 } & \multicolumn{2}{|c|}{ Value Apprippritation } \\
\hline & & & ostion & $\begin{array}{l}\text { value } \\
\text { niminghim }\end{array}$ & $\begin{array}{l}\text { proposition } \\
\text { thatait }\end{array}$ & & & 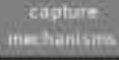 & Atructues \\
\hline \multirow{9}{*}{$\begin{array}{c}\text { Ervironment- } \\
\text { driven }\end{array}$} & \multirow{6}{*}{$\begin{array}{l}\text { Increase in } \\
\text { data traffic }\end{array}$} & Diflusion of VAS (OT) & (1) & & 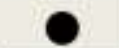 & 0 & & (1) & () \\
\hline & & Bendwidth consuming services & ( & $\Theta$ & (1) & () & ( & ( & ( \\
\hline & & Accessible data traffic plans & (1) & & (1) & $\mathrm{O}$ & $\mathrm{O}$ & 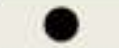 & \\
\hline & & Sotial networking sevices & () & & (1) & $\mathrm{O}$ & (1) & () & ( \\
\hline & & Smartphiones & C) & & 0 & () & () & C & ( \\
\hline & & Marketing eflorts & () & 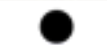 & $\mathrm{O}$ & $\mathrm{O}$ & 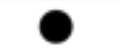 & $\mathrm{O}$ & $\mathrm{O}$ \\
\hline & \multirow{3}{*}{$\begin{array}{c}\text { Decrease in } \\
\text { voice } \\
\text { revenues }\end{array}$} & Market saturation & () & () & () & ( & O & () & C \\
\hline & & Emergence of Volp & O & (1) & () & $\mathrm{O}$ & (1) & () & ( \\
\hline & & Social networking sorvices & (1) & (1) & (1) & 0 & (1) & () & () \\
\hline
\end{tabular}

ONoimpact $($ Mediumimpact 1 very highimpact

Figure 4 - Impact of disruptive change factors in Italian MNOs' business models 